\title{
Design of Adaptive Changing Structures with Bandwidth Control for Wideband Applications
}

\author{
M. Paranthaman ${ }^{1}$, A. Berlin ${ }^{2}$ \\ Assistant Professor, Department of ECE, M. Kumarasamy College of Engineering, Karur, India ${ }^{1,2}$
}

\begin{abstract}
An adaptive changing antenna based on E-shaped structure with bandwidth controlled is discussed in this proposed work. Tuning antennas to configure dynamically or manually such that they can adapt to changing system requirements can eliminate those restrictions and offers additional functionality. A frequency reconfigurable E-shaped patch antenna can be utilized for improving the bandwidth. The bandwidth can cover the frequency range from 1.85 GHz-2.33 GHz. The performances of the proposed antenna, in terms of return losses and radiation patterns, with divergent DC bias voltages across the varactor diode, have been studied using computer simulation and measurement.
\end{abstract}

Keywords: Patch Antenna, Reconfigurable Antenna, Cognitive Radio, Two E-Shape.

\section{INTRODUCTION}

There have been interests in the field of reconfigurable antennas where the multiband capabilities can be further enhanced to incorporate multiple wireless standards [1]. Future cognitive communication systems will also require antennas capable of operating over wide bandwidth [2]. Modern wireless communication systems relying on multiband reconfigurable antennas are becoming more popular for their ability to serve multiple standards using a single compact antenna, allowing a reduction in the dimensions of the wireless device and more space to integrate with other electronic components [6].Dynamic spectrum management offers many advantages to wireless systems, including diversity and channel capacity improvement through wider bandwidths. Network architecture is one of the constraints for an antenna which is designed for cognitive radio.

Frequency reconfigurable antennas can be classified into two categories, namely continuous tuning and coarse tuning. Continuous tuning can be achieved using varactors and the antennas are allowed for smooth transitions within or between operating bands [7]. Coarse tuning can be achieved using PIN diode switches and the operating frequency is switched among different services, depending on the switching states [8].Cognitive radio is an adaptive, intelligent network technology that can be configured dynamically. In wireless spectrum available channels are automatically sensed by cognitive radio. It can be evolve as a fully reconfigurable transceiver which dynamically adapts its communication parameters to user and network demands..The coveted nature of an antenna which is designed for cognitive radio is omni-directional coverage and extremely wide bandwidth design. For cognitive radio systems patch antennas has been limited due to their narrow bandwidth. Through novel patch topologies, such as the E-shaped patch, their bandwidth can be extended. Frequency reconfigurability is also employed in E-shaped patch. For changing the state various components such as switches, diodes, optical cables and mechanical actuators are used. To access different wireless services such as Bluetooth, Wi-Fi, 3G, GPS and WiMAX over several frequency bands, multiradio wireless systems are presently being developed.[1] Multiband antennas which require complex filtering have to access those devices. Frequency Adjustable antennas with multiband potential can be used to eliminate filtering requirements. To reconfigure frequency of antenna several methods used such as PIN diodes, MEMS based design, stepper motors, optical cables and fluidic micro-pumps.

In this proposed work, we have discussed E-shaped radiators, a GCPW and four varactor diodes connecting the E-Shapes. Through the use of DC bias voltage across the varactor diodes, the bandwidth of the antenna can be controlled to be wide or narrow.

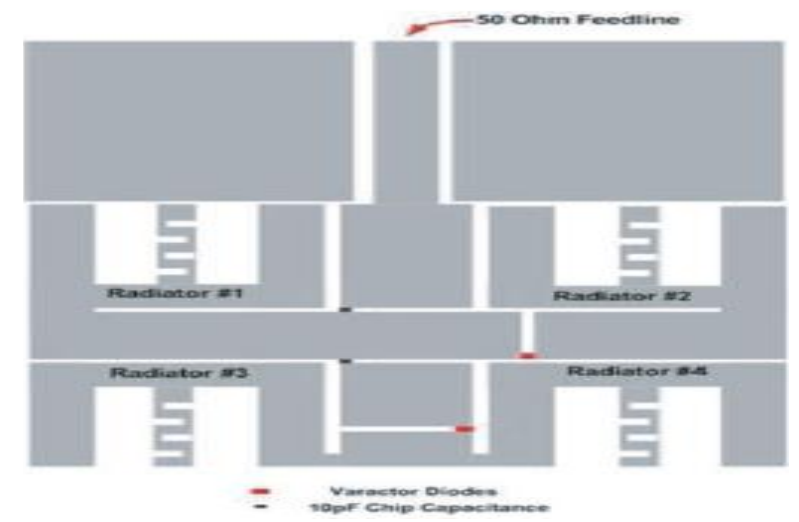

Fig.1.E-Shaped patch antenna design using simulation

In recent year's wireless communication have experienced explosive growth, it must support the increasing demand for high rates due to rapidly increasing devices.[1] In this regard, antennas used for those devices have to change based on the parameter changes. So the need for antennas 
with multiple functions is increased. In order to The dielectric constant of the substrates used in the design accomplish current and future demands, antenna is 4.4 and 1.0 respectively. The size of antenna is $120 \times 100$ parameters such as radiation pattern, operating frequency, $\mathrm{mm}^{2}$ with $50 \Omega$ probe feed. polarization are reconfigured.[2]

\section{DESIGN METHODOLOGY}

The structure of the proposed reconfigurable E-shape antenna is shown in figure.1. Where four radiators are optimized to allow the bandwidth of the antenna to be controlled over a wide range.

The varactors operate like variable capacitors. The positions of the varactor on the structure are optimized using the HFSS simulator software to achieve the widest controlled range. The antenna was fabricated using an FR4 substrate with thickness of $1.57 \mathrm{~mm}$ and a relative permittivity of 4.4. From the literature study of designed antenna starts from broadband microstrip antenna[4], single layer-single patch $U$ slot[5], double $U$ slot antenna[6]. Then the patch antenna with switchable slots came into picture The E-shaped patch antenna has single feed line and single layer.

In the simulations, the varactor diodes were modelled using Resistance, Inductance and Capacitance(RLC) boundary sheet when the capacitance of the varactor diodes varied from $2 \mathrm{pF}$ to $14 \mathrm{pF}$. The characteristic of Fig. 2 are used for the varactor diode in the simulation tests.To prove our design concept, a practical varactor diode, BB184 from NXPwith a capacitance value ranging from $2 \mathrm{pF}$ to $14 \mathrm{pF}$ controlled by a DC bias voltage varying from $1 \mathrm{~V}$ to $14 \mathrm{~V}$ was employed. The dimension of the varactor diode is approximately $1 \mathrm{~mm} 2$.

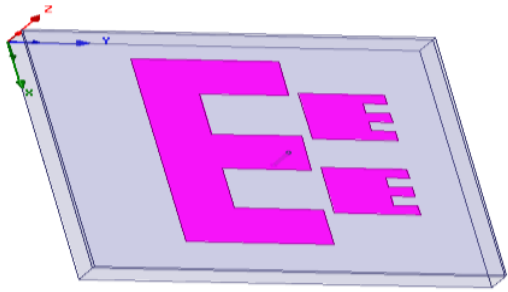

Fig.2.E-Shaped patch antenna when the switch is OFF state

The E-shaped patch antenna is simulated on FR4 substrate and the antenna design has other substrate called foam to increase the bandwidth which is placed between FR4 and ground.

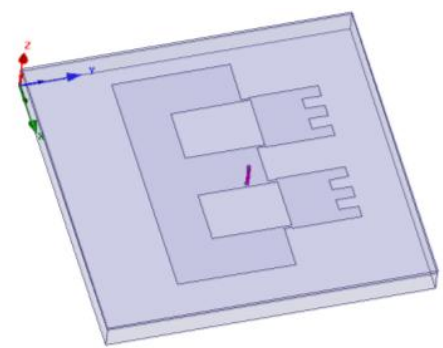

Fig.3. E-Shaped patch antenna when the switch is ON

\section{SIMULATED RESULTS}

The 2 E-Shaped patch antenna is designed and simulated using HFSS 13.0 electromagnetic simulator. Four main parameters is obtained as simulated results. The parameters are return loss, voltage standing wave ratio, radiation pattern and radiation efficiency. OFF state of the switch is represented by open circuit and ON state is represented by short circuit. A good antenna must have its return loss is less than $-10 \mathrm{~dB}$ and vswr is in the range from to 2.5 .

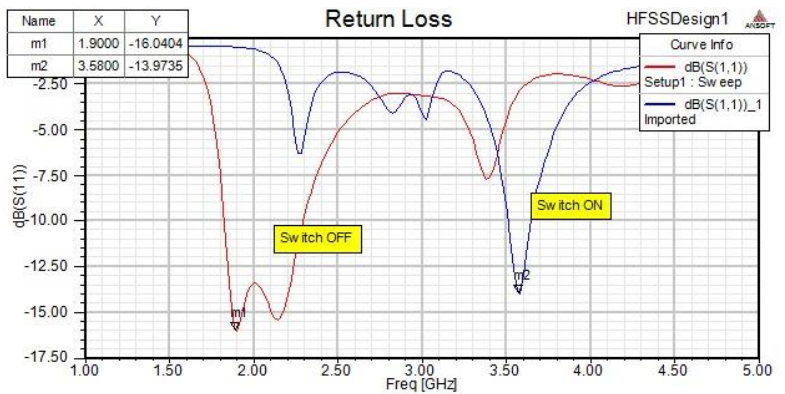

Fig.4. Return $\operatorname{loss}\left(\mathrm{S}_{11}\right)$

In Fig.4.Shows the return loss $\left(S_{11}\right)$ is less than $-10 \mathrm{~dB}$. For OFF state of the switch $-16 \mathrm{~dB}$ as the return loss at 1.9 $\mathrm{GHz}$ and for $\mathrm{ON}$ state of the switch $-13 \mathrm{~dB}$ at $3.58 \mathrm{GHz}$.

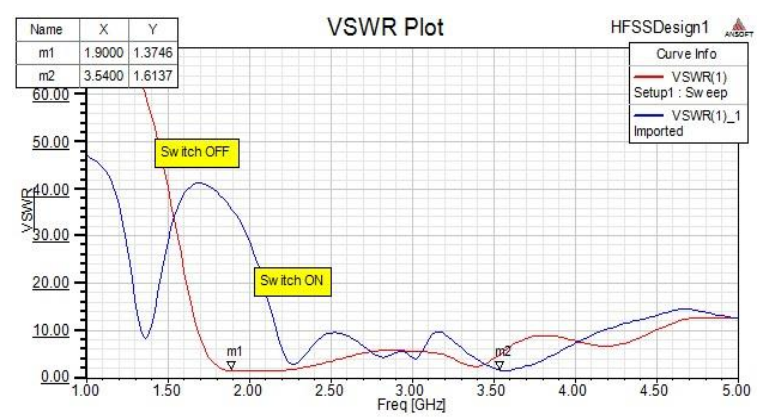

Fig.5.VSWR

Fig.5. Shows the VSWR which states that for the frequencies $1.9 \mathrm{GHz}$ and $3.58 \mathrm{GHz}$ is 1.6 and 1.3 respectively.

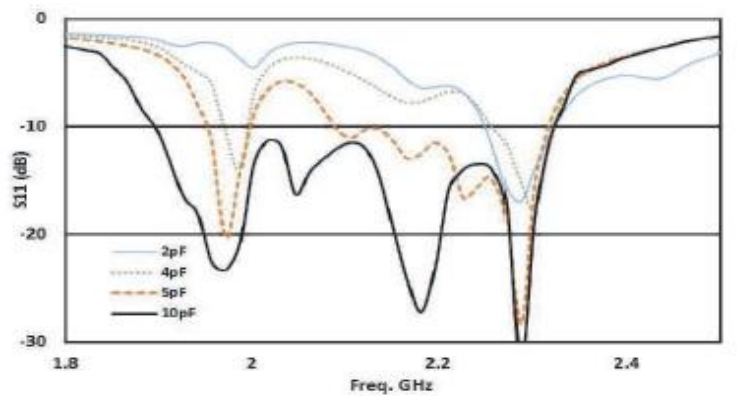

Fig.6 Effect of capacitance on Bandwidth 


\section{CONCLUSION}

Results in Fig. 7 show that, when all the varactors are fixed at $2 \mathrm{pF}$, the bandwidth of the antenna is $3.4 \%$ (for reflection coefficient $\mathrm{S} 11<-10 \mathrm{~dB}$ ). The bandwidth of the antenna can be further increased when increasing the varactor diodes respectively. It should be noted that the bandwidth-tuning concept proposed here can be extended to cover more bands or to serve the lower frequencies by using meandered line in all the E-shape. Since our target is for the mobile and Wireless applications, we have limited the meandered line structure to just in a single arm of the E-shape. The main advantages of the proposed antenna include low profile, lightweight and easy to fabricate simple structure targeting future smaller wireless communication devices and cognitive radio applications.

\section{REFERENCES}

[1] Lei Ge, and Kwai-ManLuk "A Band-Reconfigurable Antenna Based on Directed Dipole" IEEE Trans. Antennas Propag., vol.62, no. 1, pp. 64-71, Jan. 2014.

[2] S.Palanivel Rajan, "Review and Investigations on Future Research Directions of Mobile Based Telecare System for Cardiac Surveillance", Journal of Applied Research and Technology, ISSN No.: 1665-6423, Vol. 13, Issue 4, pp. 454- 460, 2015.

[3] Deepa, E., Palaniswamy, R., \& Kuppusamy, S., Effect of performance appraisal system in organizational commitment, job satisfaction and productivity. Journal Of Contemporary Management Research, 8(1), 72-82, 2014.

[4] S.Palanivel Rajan, "A Significant and Vital Glance on "Stress and Fitness Monitoring Embedded on a Modern Telematics Platform", Telemedicine and e-Health Journal, ISSN: 1530- 5627 (Online ISSN: 1556-3669), Vol. No.: 20, Issue No.: 8, pages: 757-758, 2014.

[5] R.Renuka, V.Kavitha, "A Performance Analysis of Load Balanced Deflection Routing with Priority Scheduling in OBS Networks", International Journal of Engineering, Science and Technology, Vol. 5, Issue 4, pp.7-13, 2013.

[6] S.Palanivel Rajan, T.Dinesh, "Analysis of Human Brain Disorders for Effectual Hippocampus Surveillance", International Journal of Modern Sciences and Engineering Technology, ISSN 2349-3755, Vol. No.: 2, Issue No.: 2, pages: 38-45, 2015.

[7] S.Palanivel Rajan, K.Sheik Davood, "Performance Evaluation on Automatic Follicles Detection in the Ovary", International Journal of Applied Engineering Research, ISSN No.: 0973- 4562, Vol. 10, Issue 55, pp. 1-5, 2015.

[8] Elliott R. Brown "RF-MEMS Switches for Reconfigurable Integrated Circuits" IEEE Transactions on Microwave Theory and Techniques, vol. 46, no. 11,pp 1868-1880, 1998

[9] S.Palanivel Rajan, R.Sukanesh, "Experimental Studies on Intelligent, Wearable and Automated Wireless Mobile Tele-Alert System for Continuous Cardiac Surveillance", Journal of Applied Research and Technology, ISSN No.: 1665-6423, Vol. No. 11, Issue No.: 1, pp.133-143, 2013.

[10] S.Vijayprasath, S.Palanivel Rajan, "Performance Investigation of an Implicit Instrumentation Tool for Deadened Patients Using Common Eye Developments as a Paradigm", International Journal of Applied Engineering Research, ISSN No.: 0973-4562, Vol. 10, Issue No.1, pp. 925-929, 2015.

[11] R.Renuka, V.Kavitha, "A Performance Analysis of Load Balanced Deflection Routing with Priority Scheduling in OBS Networks", International Journal of Engineering, Science and Technology, Vol. 5, Issue 4, pp.7-13, 2013.

[12] C Vivek, S Palanivel Rajan, V Kavitha, "Implementation of High Speed Area Efficient Variable Latency Adder", Asian Journal of Research in Social Sciences and Humanities, Vol. 6, Issue : 9, pp.306-316, 2016
[13] V.Kavitha, C.Gayathri, "A Survey on Detection Methods for Network Layer Attacks in WMN's", International Journal of Applied Engineering Research, Vol.10, Issue 1, pp.744-748, 2015.

[14] T. Huynh and K.-F. Lee, "Single-layer single-patch wideband microstrip antenna," Electron. Lett, vol. 31, pp. 1310-1312, Aug.1995.

15] S.Palanivel Rajan, et.al., "Intelligent Wireless Mobile Patient Monitoring System”, IEEE Digital Library Xplore, ISBN No. 9781-4244-7769-2, INSPEC Accession Number: 11745297, IEEE Catalog Number: CFP1044K-ART, pp. 540-543, 2010

[16] Y.X. Guo, K.M. Luk, K.F. Lee and Y.L. Chow,"Double U slot rectangular patch antenna" Electron.Lett.vol.34.no.19, Sep1988.

[17] S.Palanivel Rajan, T.Dinesh, "Systematic Review on Wearable Driver Vigilance System with Future Research Directions", International Journal of Applied Engineering Research, ISSN No.: 0973-4562, Vol. 10, Issue No.1, pp. 627-632, 2015.

[18] Mohanpriya S., Vadivel M, "Automatic Retrieval of MRI Brain Image using Multiqueries System”, IEEE Conference, pp 1099$1103,2013$.

[19] S. Palanivel Rajan, M. Paranthaman, Dr. C. Vivek, "Design and Enhancement of Wideband Reconfigurability using Two E-Shaped Patch Antenna", Asian Journal of Research in Social Sciences and Humanities, ISSN No.: 2249-7315, Vol. No.: 6, Issue: 9, pp. 317327, 2016.

[20] V.Kavitha, V.Palanisamy, "New Burst Assembly and Scheduling T technique for Optical Burst Switching Networks", Journal of Computer Science, Vol. 9, Issue 8, pp.1030-1040, 2013.

[21] S. Palanivel Rajan, M.Poovizhi, "Design of Patch Antenna Array for Radar Communication", Journal of Chemical and Pharmaceutical Sciences, ISSN No.: 0974-2115, Special Issue: 8, pp. 38-40, 2016.

22] V.Kavitha, V.Palanisamy, "Simultaneous Multi-path Transmission for Burst Loss Recovery in Optical Burst Switching Networks", European Journal of Scientific Research, Vol. 87, Issue 3, pp.412416, 2012.

[23] S.Palanivel Rajan, "Diagnosis of Cardiovascular Diseases using Retinal Images through Vessel Segmentation Graph", Current Medical Imaging Reviews, Online ISSN: 1875-6603, ISSN: $1573-$ 4056, Vol. : 13, DOI : 10.2174/1573405613666170111153207, 2017. 